\title{
METEORIZACIÓN Y EROSIÓN EN EL SUB-DESIERTO DE TABERNAS, ALMERÍA
}

\author{
A. SOLÉ BENET ${ }^{(1)}$, Y. CANTÓN ${ }^{(2)}$, R. LÁZARO ${ }^{(1)}$ y J. PUIGDEFÁBREGAS ${ }^{(1)}$ \\ (1) Estación Experimental de Zonas Aridas, Consejo Superior de Investigaciones Científicas, \\ C. General Segura, 1, 04001-Almería. \\ (2) Departamento de Edafología y Química Agrícola, Escuela Politécnica Superior, \\ Universidad de Almería, 04120-La Cañada de San Urbano. \\ correo electrónico de contacto: albert@eeza.csic.es
}

\begin{abstract}
RESUMEN. El área acarcavada, o malpaís, de mayor extensión del sudeste peninsular, en el sub-desierto de Tabernas, Almería, es un mosaico de teselas en donde se encuentran concentradas muchas de las formas de erosión de la mayoría de paisajes fluviales, y muy en especial los de zonas áridas. Un clima Mediterráneo semiárido, cercano a su extremo más árido, y una particular litología sobre una alternancia de margas yesíferas y calcarenitas explican la enorme variedad de geoformas de este paisaje. Si bien la geomorfología de la zona sugiere elevadas tasas de erosión, las particulares condiciones climáticas, con escasez de eventos de elevada intensidad y/o magnitud impiden que la erosión sea elevada. Se explican sucintamente los principales procesos geomorfológicos que han configurado este malpaís: desde la meteorización de la principal roca madre, la marga yesífera, pasando por la formación de regolitos, suelos y sus costras superficiales y un conjunto muy particular de comunidades vegetales que conviven con los procesos erosivos y las peculiares condiciones climáticas, los grupos de factores ecológicos más importantes y típicos de la zona.
\end{abstract}

ABSTRACT. The largest badlands in SE Spain, within the Tabernas sub-desert (Almería, Spain) is a mosaic of physiographic units concentrating most of the water erosion features of fluvial landscapes, specially those from arid regions. A Mediterranean semiarid climate in its driest end, along a main lithology on gypsum-calcaric mudstones, all explain the large variability of this landscape. Though the local geomorphology might suggest large erosion rates, the special climatic conditions of the area, with scarce rainfall events usually of low magnitude and intensity, restrict soil erosion. In this chapter the main geomorphic processes which have shaped the area are reviewed: from weathering, to regolith and soil formation, along with the indispensable role played by plant cover and its co-evolution with erosion. 
Palabras clave: regolito, yeso, meteorización, alternancias climáticas, líquenes. Key words: Regolith, gysum, weathering, climatic oscillations, lichens.

Enviado el 15 de septiembre de 2008 Aceptado el 18 de enero de 2009

\section{Introducción}

El subdesierto de Almería (Fig 1) contiene un malpaís o paisaje de badlands de los más extensos de la Península Ibérica. El carácter Mediterráneo semiárido de su clima y su particular litología, en la que alternan margas yesíferas y calcarenitas, le confieren un especial interés para muchas disciplinas del ámbito de las Geociencias y la Ecología. En los últimos años, el subdesierto de Tabernas ha visto multiplicar el número de visitas escolares y universitarias así como el número de proyectos de investigación y publicaciones científicas, tanto nacionales como internacionales, debido a que, como muchas áreas de malpaís, es un auténtico laboratorio natural en el que el predominio de superficies desnudas o con escasez de vegetación facilita la observación y medición detallada de los procesos geo-ecológicos. De todos ellos, los geomorfológicos son especialmente visibles y constituyen el marco ideal para estudiar la conexión entre la litología, el suelo, la vegetación y el clima. Por otra parte, la posibilidad de expansión de estas áreas y los efectos aguas abajo (de escorrentías con gran carga sólida y a veces salina, que se generan muy rápidamente) incitan a aumentar el conocimiento de estas zonas y en especial en un contexto de cambio global.

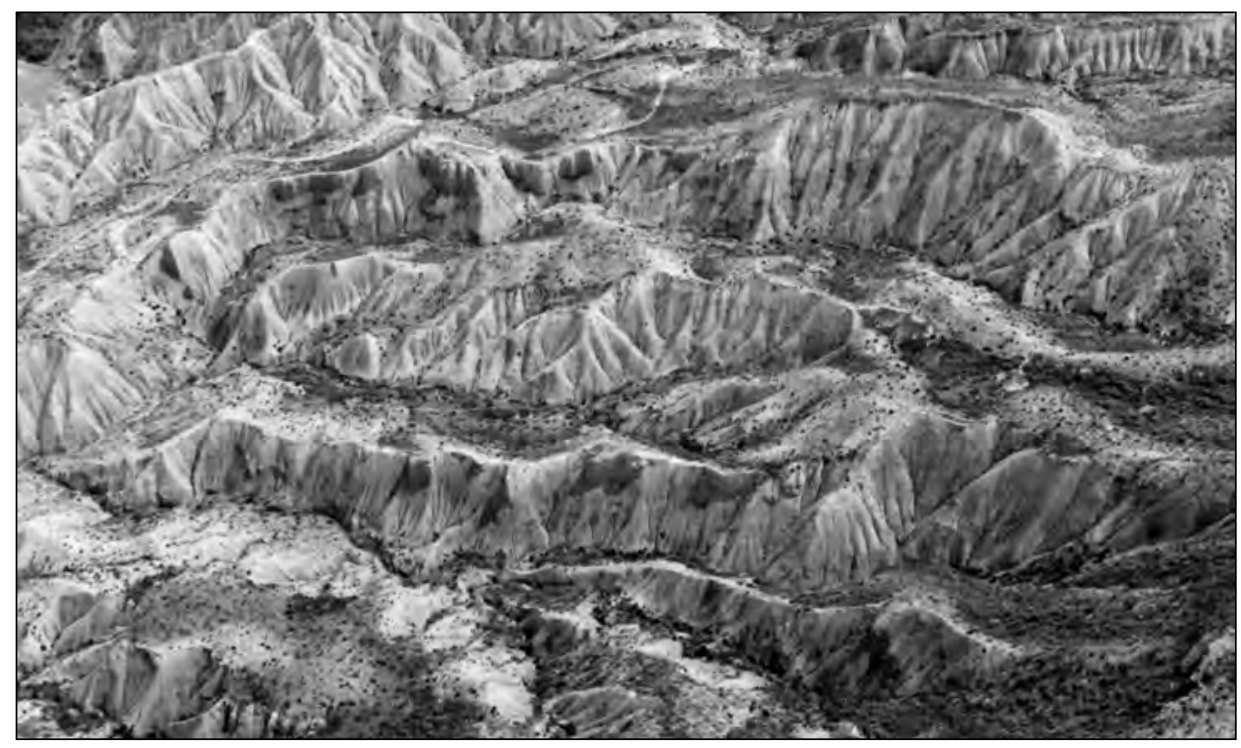

Figura 1. Vista aérea de los badlands de Tabernas (foto Chadwick) 
En este artículo se repasan los trabajos desarrollados en los últimos años en la zona y muy en especial en el área experimental El Cautivo (Fig 2) que forma parte de la Red de Estaciones Experimentales de Seguimiento y Evaluación de la Erosión y Desertificación (RESEL, 1996). Se explican sucintamente los principales procesos geomorfológicos que han configurado este malpaís: desde la meteorización de la principal roca madre, la marga yesífera, pasando por la formación de regolitos, suelos y sus costras superficiales que soportan un conjunto muy particular de comunidades vegetales que conviven, adaptándose constantemente, con los procesos erosivos y la elevada variabilidad inter- e intra-anual de los factores climáticos de la región.

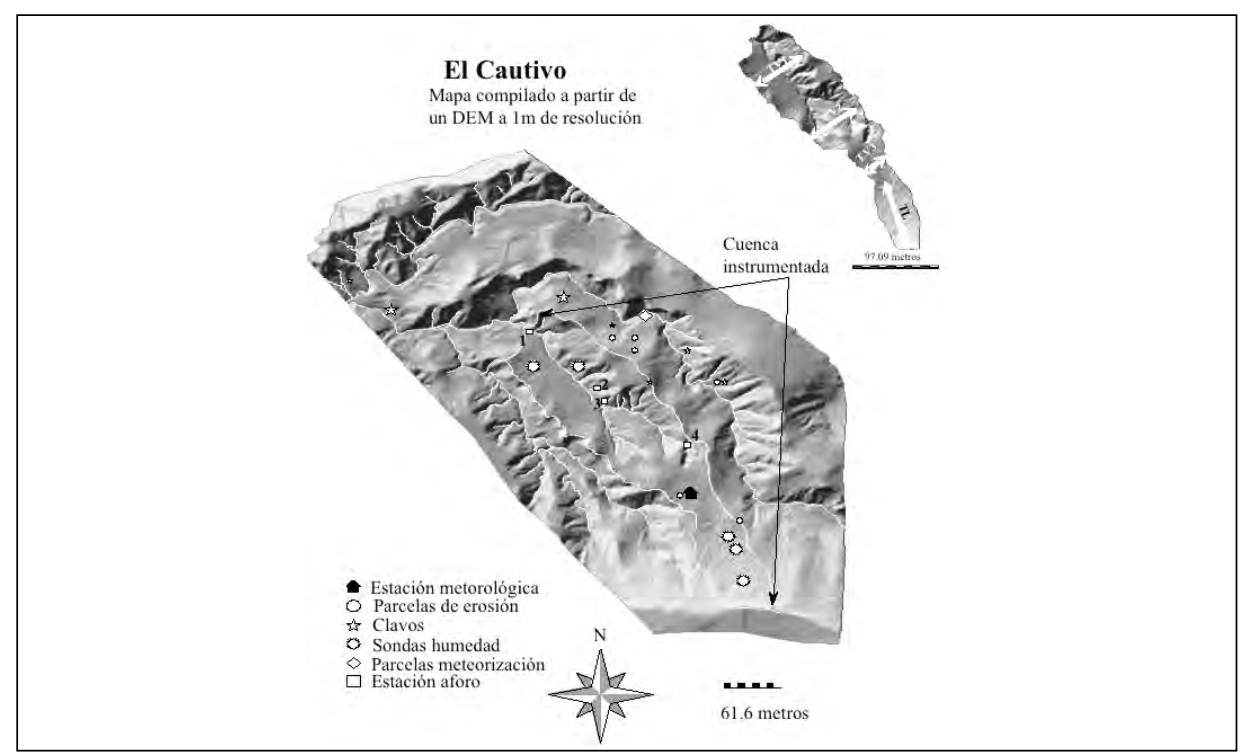

Figura 2. Mapa del área experimental El Cautivo en el que se indican algunas instalaciones. Compilado a partir de un MDE a $1 \mathrm{~m}$ de resolución

\section{Marco geográfico y geológico}

El sub-desierto de Tabernas (Fig 1) se encuentra a unos $20 \mathrm{~km}$ al $\mathrm{N}$ de la ciudad de Almería, y forma parte de la unidad tectónica formada por la cuenca Neógena de Tabernas al E y del corredor de Canjáyar al W. Está limitado por las Sierras Nevada al Noroeste, de Gádor al Suroeste, de los Filabres al Norte y Alhamilla al Sureste, todas ellas pertenecientes a las Béticas. La cuenca se formó por el plegamiento y fallamiento del zócalo metamórfico a partir del Serravallense, hace 10 millones de años, rellenándose sucesivamente desde dicha época hasta el Pleistoceno por sedimentos marinos primero y continentales después (Weijemars, 1991). En todo este período se depositaron areniscas, margas, calizas arrecifales y yesos. Durante el Tortoniense sedimentaron potentes series turbidíticas (400 a $500 \mathrm{~m}$ ), con la típica alternancia en estratos desde $10 \mathrm{~cm}$ a más de $1 \mathrm{~m}$ de margas bioturbadas y calcarenitas, correspondientes a abanicos deltaicos (Kleverlaan, 1989). 
Durante el Cuaternario los levantamientos y las disecciones se fueron sucediendo dando lugar a un paisaje escalonado con distintos niveles de encajamiento de distintas edades separados por terrazas aluviales o depósitos coluviales que cubren los sedimentos blandos, las margas, que han dado lugar al malpaís. Este escalonamiento del malpaís origina una morfología de cuestas esencialmente de origen tectónico, desarrollado en paralelo con una alternancia de climas secos y húmedos durante el Cuaternario (Rohdenburg y Sabelberg, 1973). Se identifican al menos tres niveles que corresponden a sendos estadios de erosión y sedimentación (Harvey y Calvo, 1991). Dentro de la cuenca de Tabernas, la zona de malpaís ocupa una extensión de 5540 ha, entre 220 m y 660 $\mathrm{m}$ de altitud, la más extensa del sudeste peninsular.

\section{Litología}

La principal roca que da lugar al malpaís es una marga yesífera o limolita calcoyesífera, constituida en un 50\% por minerales silícicos (moscovita, paragonita, clorita, cuarzo y feldespatos en orden decreciente de abundancia) y el resto por calcita, yeso y dolomita y algo de halita (Solé-Benet et al., 1997; Cantón et al., 2001b). El tamaño de los minerales es esencialmente limoso y muy homogéneo, con un $\mathrm{D}_{60}$ entre 25 y $20 \mu \mathrm{m}$, un $\mathrm{D}_{10}$ entre $2 \mu \mathrm{m}$ y $3,7 \mu \mathrm{m}$ y un coeficiente de uniformidad $\left(\mathrm{D}_{60} / \mathrm{D}_{10}\right)$ de 6,5 (Solé, datos inéditos). Según Therzaghi y Peck (1967) y Taylor y Smith (1968) la distribución granulométrica del material tiene un papel esencial en la resistencia al esfuerzo de cizalla y en la susceptibilidad a la erosión: cuanto más amplio es el rango de tamaños de partícula, mayor es el grado de empaquetamiento del material y mayor es su resistencia al esfuerzo de cizalla y a la erosión. Las margas de Tabernas, al tener un rango granulométrico reducido, con una proporción mayoritaria de limos finos $(2-20 \mathrm{~mm})$, tienen un bajo grado de empaquetamiento, por lo que tienen poca resistencia al esfuerzo de cizalla y son muy susceptibles a la erosión.

En la estabilidad del material, aparte de la granulometría y el grado de consolidación de la roca (los sedimentos Tortonienses de Tabernas se definen como escasamente consolidados) también interviene el cemento entre los granos constituyentes. En Tabernas el compuesto cementante principal es el yeso, la calcita y algo de halita, todos ellos solubles en agua (Cantón et al., 2001b) dado el pequeño tamaño de los cristales. La solubilidad de estos cementos se ve favorecida por la particular microestructura de la roca, atravesada por una densa red de microfisuras, fisuras y grietas debidas a las fuerzas de descompresión resultantes de la exhumación del material previamente confinado bajo varias decenas de metros de sedimentos pliocenos y cuaternarios. Los datos de porosimetría por intrusión de $\mathrm{Hg}$ desde la roca fresca hasta el regolito cerca de la superficie, indican un aumento progresivo de la porosidad, desde el 9\% (valor relativamente alto para una roca) hasta el 66\% en volumen (Cantón et al., 2001b). En la tabla 1 se muestran las granulometrías de materiales del área acarcavada de Tabernas comparadas con las de otras áreas de malpaís del entorno Mediterráneo. 


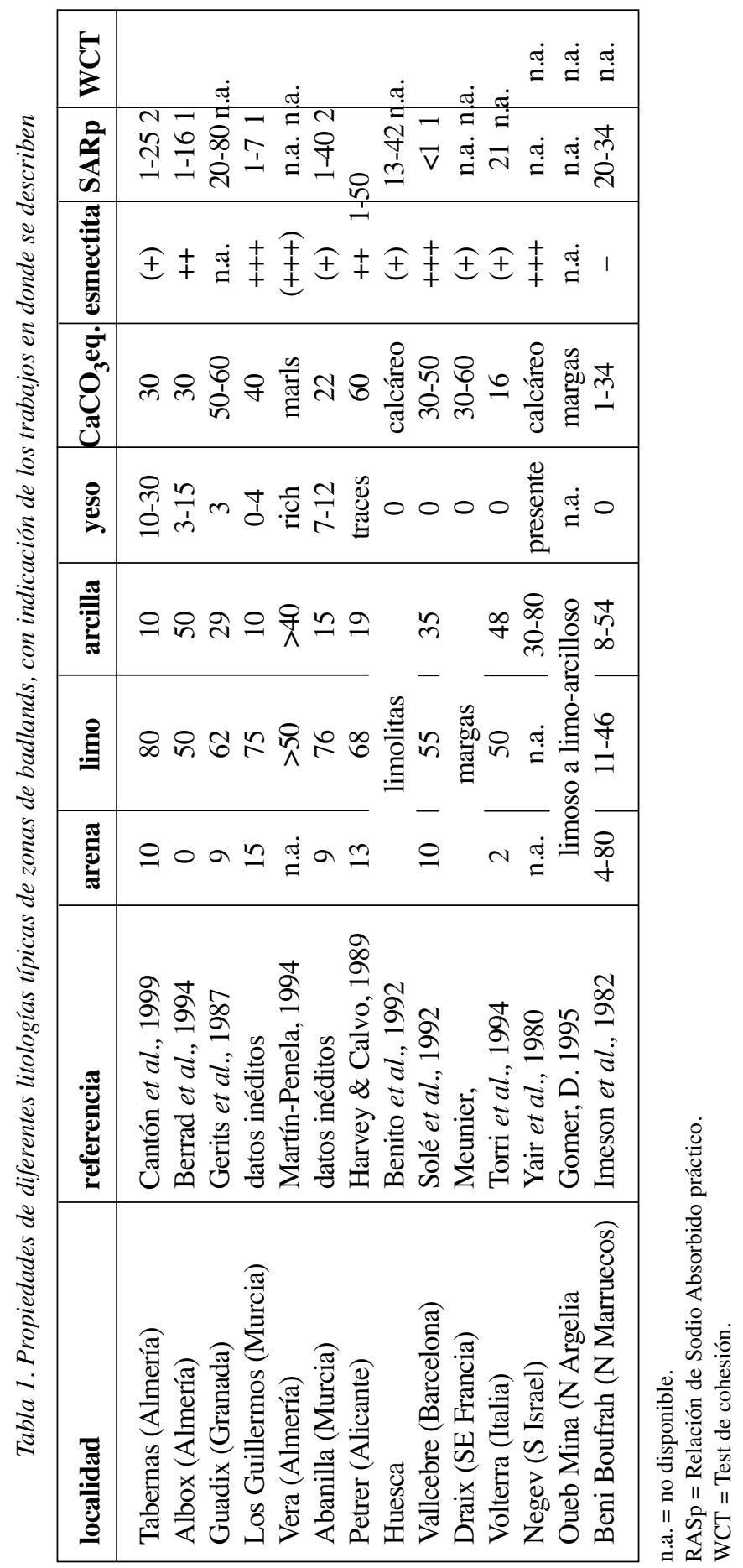


Otras propiedades físicas características de las litologías propensas a producir malpaís son los límites de Atterberg y la cohesión (índice de Emerson). El índice de Atterberg, Ip (diferencia entre el límite plástico y el límite líquido) constituye un buen índicador de la reactividad del material frente al agua. Cuanto mayor es este índice, mayor es la estabilidad del material. Las margas, limolitas y sus productos de alteración suelen tener Ip bajos (entre 5 y 12 en tabla 1). En cuanto a la cohesión, o bien su carácter opuesto, la disgregación, puede evaluarse mediante la prueba de cohesión o water coherence test (Emerson, 1967) que, en el caso de Tabernas (tabla 1) presenta índices de cohesión muy bajos (elevada disgregación), y similares a los de otras áreas de malpaís.

También algunas propiedades químicas, como la sodicidad, expresada como el PSA (porcentaje de sodio absorbido) que satura parte del complejo de intercambio del suelo (arcilla y materia orgánica), afectan la estabilidad de los agregados. Cuando el PSA es superior a 13 las arcillas se dispersan al humedecerse el material, destruyéndose los agregados por lo que difícilmente puede resistir el impacto erosivo del agua (SSSA, 1997). La mayoría de suelos y regolitos de Tabernas presentan valores de PSA inferiores a 5, si bien en algunos casos de acumulación de sales se han medidos valores entre 8 y 13 , lo que indica cierto riesgo de dispersión.

\section{Clima}

El rasgo principal del clima de SubDesierto de Tabernas es su aridez, debida a que la mayor parte de los frentes de lluvia proceden del Atlántico y el área queda a sotavento de las sierras béticas. Según el índice de aridez de Thornthwaite, se trata de la zona más árida de la Península Ibérica (Capel, 1982), e incluso de Europa (Neumann, 1961). El carácter mediterráneo y las temperaturas suaves son asimismo rasgos típicos de la región.

La precipitación media anual es de $239 \mathrm{~mm}$ (para un registro de 30 años en la estación de Tabernas, 1967-1997), oscilando entre 115 mm y $431 \mathrm{~mm}$, con un número de días de lluvia $(\geq 1 \mathrm{~mm}$ ) por año que oscila entre 25 y 55 (promedio = 37). Pero sólo un $6 \%$ de los episodios lluviosos superan los $20 \mathrm{~mm}$ y sólo un $0.7 \%$ supera los $50 \mathrm{~mm} \mathrm{día}^{-1}$. Hay un máximo en Octubre-Noviembre y un mínimo en Julio-Agosto, con valores también altos en invierno. Las intensidades máximas de precipitación registradas han sido de $98 \mathrm{~mm}$ en 24 horas, $108 \mathrm{~mm} \mathrm{~h}^{-1}$ en 5 minutos y $83,8 \mathrm{~mm} \mathrm{~h}^{-1}$ en 10 minutos.

La temperatura media anual es de $18,6^{\circ} \mathrm{C}$ en nuestra estación de El Cautivo, a 300 m s.n.m. de altitud, con medias mensuales oscilando entre $10,2^{\circ} \mathrm{C}$ (Enero) y $27,9^{\circ} \mathrm{C}$ (Agosto). La media de las máximas diarias del mes más cálido es de $34.5^{\circ} \mathrm{C}$ y la media de las mínimas del mes más frío, $6.1^{\circ} \mathrm{C}$. Las oscilaciones absolutas (diferencia entre la máxima y mínima absolutas de cada mes, promedio del periodo) alcanzan entre $30 \mathrm{y}$ $35^{\circ} \mathrm{C}$ todos los meses (Lázaro et al., 2004).

La humedad relativa media del aire oscila entre el 51-52\% en Julio y Agosto y el 65-66\% en Diciembre y Enero. Pero las oscilaciones en ciclos de pocos días, incluso 
dentro de un mismo día, suelen ser más fuertes que las anuales. En cualquier mes del año se puede alcanzar o superar el 97\%. Las medias de las mínimas oscilan entre el 30\% (Julio y Agosto) y el 46\% (Diciembre y Enero) (Lázaro et al., 2004).

La radiación solar total incidente alcanza máximos diarios de alrededor de $1000 \mathrm{w} \mathrm{m}^{-2}$ en los meses de días largos, con cielo despejado, soliendo superar los $900 \mathrm{w} \mathrm{m}^{-2}$ aproximadamente entre las 12:30 y las 16 horas (hora local). Estos máximos se dan durante 4 ó 5 meses al año, a partir de mediados de abril. En los días más cortos los máximos están entre 500 y $600 \mathrm{~W} \mathrm{~m}^{-2}$ (si no hay nubes) (Lázaro et al, 2004).

La evapotranspiración potencial (ETP) promedio calculada con el método de Penman para la estación de Tabernas es de 779,5 mm por lo que el índice P/ETP es de 0,3, es decir semiárido, sin embargo para Thornwaite (1948) la zona pertenece a la categoría árida (Palacio, 2002). Una estima por el método de Blaney y Criddle. modificado por Doorrenbos y Pruitt (1976), da una ETP total anual media de $1666 \mathrm{~mm}$ para la estación de Tabernas. La ETP es siempre varias veces mayor que la precipitación $(\mathrm{P})$, si bien oscila de unos a otros años y sobre todo de unos meses a otros. En el mes con mayor cociente P/ETP, Noviembre, la capacidad del medio para evaporar y transpirar sigue siendo triple que la precipitación. En el mes de Julio, la ETP alcanza unas 100 veces el valor de la precipitación.

\section{Meteorización, regolito y costras superficiales}

La característica esencial del malpaís es la falta total o parcial de suelo en la mayor parte de su superficie. Sin embargo, para que la erosión pueda actuar sobre la roca madre, es necesario que el material esté preparado. Aquí intervienen los procesos de meteorización.

En Tabernas, contrariamente a lo que podría pensarse por tratarse de una zona árida, es muy importante la meterozación química, como se ha comprobado en un doble experimento in vitro y en el campo. En el laboratorio se sometieron una serie de réplicas de bloques de marga fresca a ciclos de humedecimiento (hasta saturación)-desecación (a $40^{\circ} \mathrm{C}$ ), registrando el peso de los bloques después de cada ciclo y analizando la mineralogía y la química después de cada serie de 5 ciclos. Al aumentar el número de ciclos, la porosidad de las muestras, deducida por la absorción de agua, aumentó potencialmente de forma que unos pocos ciclos son suficientes para aumentar el espacio poroso, sobre todo de tipo fisural, que ayuda a fragmentar y disgregar la roca (Fig. 3). Estos mismos ciclos de humectación-desecación fueron suficientes para revelar la migración de los iones $\left(\mathrm{Na}^{+}, \mathrm{Ca}^{2+}, \mathrm{Mg}^{2+}, \mathrm{SO}_{4}^{-}, \mathrm{HCO}^{-}, \mathrm{y} \mathrm{Cl}^{-}\right)$de la marga, lo que explica la solubilización del una parte del material (yeso, calcita, halita) (Cantón, 2001; Cantón et al., 2001b).

Así pues, el yeso y su presión de cristalización son los principales responsables de la meteorización junto con los ciclos humedecimiento-desecación que se producen a consecuencia de la alternancia entre lluvias y períodos secos, y la consiguiente disolución y eliminación parcial o total del yeso (Cantón et al., 2001b). 


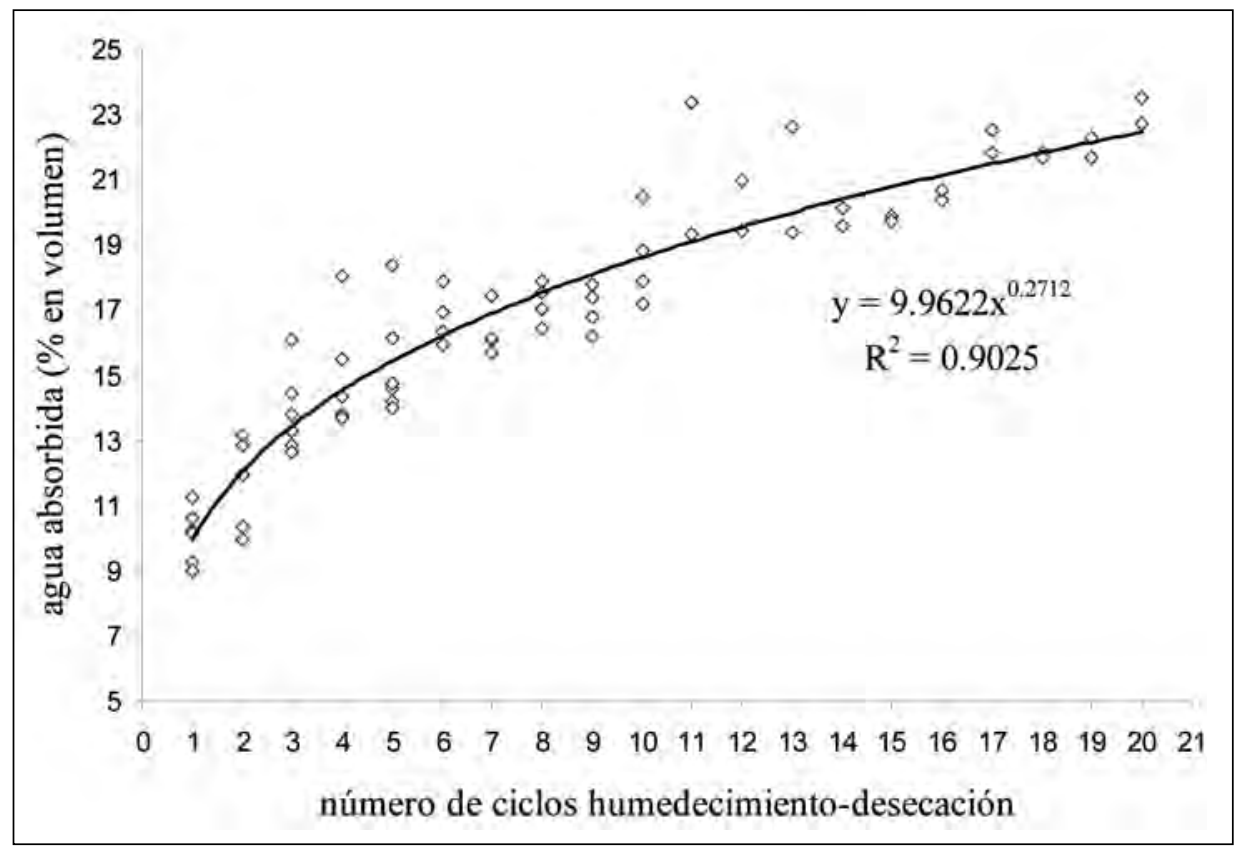

Figura 3. La evolución del agua absorbida durante un experimento de meteorización (20 ciclos humedecimiento-desecación) de bloques de marga inicialmente fresca, sigue una función potencial (según Cantón et al., 2001)

En parcelas de meteorización en el campo se midieron tasas de rebajamiento entre $8 \mathrm{~mm}$ año ${ }^{-1}$ y $0.7 \mathrm{~mm}$ año-1 según se retirara o no el material meteorizado cada seis meses. Aparte de indicar que la capa de regolito protege al suelo de la meteorización, las tasas de rebajamiento semestral mostraron una correlación significativa con el número de episodios de lluvia superiores a $3 \mathrm{~mm}$ ocurridos en dichos períodos, ratificando los resultados del ensayo in vitro (Cantón et al., 2001a).

Una vez formado el regolito, su evolución puede ser compleja, y suele pasar por la formación de costras superficiales que empiezan siendo minerales (de tipo estructural y deposicional, según Valentin y Bresson, 1992) y que se mantienen casi siempre en las laderas orientadas al sur, pero pueden evolucionar hasta costras biológicas (microfíticas primero y finalmente líquénicas) cuando las condiciones microclimáticas y de estabilidad lo permiten (Alexander y Calvo, 1990; Lázaro-Suau, 1995; Solé-Benet et al., 1997).

La consecuencia más importante de estas costras superficiales es que condicionan las propiedades hidrológicas de regolitos y suelos: la infiltración se ve afectada y la respuesta a la lluvia suele ser rápida, siendo los tiempos hasta producir escorrentía muy breves, entre 2 y 4 minutos (lluvia simulada de $50 \mathrm{~mm} \mathrm{~h}^{-1}$ ) (Solé-Benet et al., 1997; Chamizo et al., 2008). Además, las costras biológicas mitigan las oscilaciones de temperatura y humedad en el suelo subyacente, aunque no tanto como la vegetación vascular. 


\section{Suelos y vegetación}

Se observan patrones de distribución espacial de la cubierta del suelo que se repiten por todo el área acarcavada. En las laderas más inclinadas y orientadas al S, SW y W no aparece cubierta vegetal, mientras que las laderas orientadas al N, NE y E, menos inclinadas, están vegetadas. Además las diferentes clases de vegetación, en términos de especies y tipos funcionales, se distribuyen de acuerdo con la geomorfología (Lázaro et al., 2000). Cantón et al. (2004a), a partir de la regionalización de los atributos topográficos extraídos de un Modelo Digital de Elevaciones ( $1 \mathrm{~m}$ de resolución) y la cartografía detallada de los tipos de cubiertas, demostraron que la topografía controla la distribución espacial de la cubierta del suelo. Por otra parte, el análisis de la abundancia de cada tipo de cubierta a través del gradiente de cada variable topográfica mediante pruebas de regresión lineal en tablas r x 2 (Cantón et al., 2004a) permitió demostrar que las cubierta del suelo se organizan a lo largo de gradientes topográficos, de forma que las superficies vegetadas son más abundantes donde las pendientes son bajas, las laderas cóncavas, las áreas de contribución relativamente grandes y con bajo potencial para el transporte de sedimentos. Las superficies no vegetadas muestran la tendencia contraria y las superficies en las que domina la cubierta liquénica están asociadas a condiciones intermedias.

En el malpaís es importante distinguir entre los suelos desarrollados y los regolitos que son el paso previo a su formación.

Las cárcavas y las laderas con fuerte pendiente, en general orientadas al S, SW y $\mathrm{W}$, no permiten la formación de verdaderos suelos porque la erosión es frecuente y/o intensa. Se trata de los regolitos margosos, sin estructura edáfica, clasificados según FAO-ISRIC-ISSS (1998) como Regosoles Epilépticos (Cantón et al., 2003). Se caracterizan por presentar muy baja capacidad para retener agua y tienen altos contenidos en limo, carbonatos, yeso y sales en general y características químicas similares a las del material parental (marga). En estos regolitos o bien no hay cubierta vegetal o es muy incipiente, formada por pequeños rodales de criptógamas, arbustos aislados de la especie Salsola genistoides, una anual de densidad muy variable según los años, Moricandia foetida, y a veces también Reseda media y Fagonia cretica.

En las partes bajas de estas mismas laderas orientadas al S, SW y W y en las partes más altas de laderas orientadas al N, NE y E el regolito suele estar recubierto por una capa de limos (depositados en las laderas $\mathrm{S}$ e in situ en las $\mathrm{N}$ ) que permite la formación de un suelo incipiente, con una estructura débil granular y una capacidad para retener agua algo mayor, contenidos en carbonatos y yeso bastante elevados, pero con el yeso y los iones solubles lavados en el primer horizonte. Se trata de Regosoles Endolépticos (Cantón et al., 2003). Suelen estar cubiertos de costras biológicas dominadas por cianobacterias, que incluyen diversos líquenes colonizadores (Placynthium nigrum, Endocarpon pusillum, Fulgensia fulgida, Collema sps.) cuando están en las laderas S, SW y W y por costras dominadas por líquenes (Diploschistes diacapsis, Squamarina lentigera, Lepraria crassissima, Buellia sps....) en las partes altas de laderas N, NE y E. 
Los suelos con horizontes bien diferenciados suelen encontrarse en superficies más estables, ya sea por la evolución del material in situ, o bien porque los sedimentos acumulados en áreas con escasa pendiente (pedimentos o terrazas aluviales) favorecen dicha evolución (Gallart et al., 2002). Cantón et al (2003) han identificado los siguientes tipos de suelo:

Gypsisoles Eutricos (FAO-ISRIC-ISSS, 1998), que aparecen en dos condiciones topográficas específicas: divisorias en niveles antiguos y la parte alta de la cabecera de El Cautivo, una ladera con fuerte pendiente orientada al $\mathrm{N}$, ambas con áreas de contribución pequeñas, sobre todo en la cuerda, y con elevada capacidad de infiltración, de manera que no se genera escorrentía significativa ni lavado lateral del yeso; las divisorias suelen presentar una cubierta de costras biológicas con predominio de líquenes y pequeños arbustos dispersos como Helianthemum almeriense, Sideritis pusilla, Launaea lanifera, Euzomodendron bourgeanum; la cabecera de la cuenca, presenta cubierta de líquenes y matas dispersas de esparto (Stipa tenacísima).

Regosoles Calcaricos (FAO-ISRIC-ISSS, 1998), que aparecen en la parte media a baja de la cabecera de la cuenca y en laderas orientadas al $\mathrm{N}$, en las que se conserva parte de la calcoarenita y aparecen suelos más arenosos, profundos y más lavados en sales. La vegetación típica es un espartal poco denso o una mezcla de espartal y matorral de bajo porte. A menudo domina el esparto (Stipa tenacissima), siendo también frecuentes y típicas Dactylis glometa ssp hispanica, Hamada articulata Thymus hyemalis, Asparagus horridus, Stipa parviflora y Sideritis

Finalmente, los Calcisoles Háplicos (FAO-ISRIC-ISSS, 1998) se localizan en pedimentos y mesas con baja pendiente, amplias áreas de contribución, bajo potencial para el transporte de sedimentos y elevada infiltración. Todas estas características favorecen la meteorización, el lavado y la edafogénesis. La vegetación es un mosaico de matorral de bajo porte (Helianthemum almeriense, Hamada articulata, Salsola genistoides, Salsola papillosa, Anabasis articulata, Launaea lanifera, Artemisia barrelieri...) y pequeños prados de herbáceas anuales (Stipa capensis, Plantago ovata, Bromus rubens, Linum strictum, Diplotaxis virgata...).

El registro de la humedad del suelo a intervalos de 15 minutos durante un año y medio bajo las distintas cubiertas y posiciones topográficas (Cantón et al., 2004b) permitió comprobar que existe una gran variabilidad en el contenido de agua en estos suelos ligada a las diferencias en la cubierta y propiedades del suelo. No se encontraron relaciones significativas cuando comparamos la humedad antecedente al evento y el coeficiente de escorrentía (Cantón et al., 2004b). Sin embargo un análisis a una escala temporal más detallada permitió comprobar que en eventos con múltiples picos de lluvia, cuando el suelo está casi saturado unos pocos milímetros de lluvia son suficientes para generar de nuevo escorrentía. El efecto de la humedad antecedente en estos casos es difícil de establecer ya que podría explicarse porque la propia humedad antecedente afecta a la tasa de infiltración, como demuestran otros autores (Bowyer-Bower, 1993) o porque el suelo se haya encostrado y disminuya la infiltración (Fig. 4). 


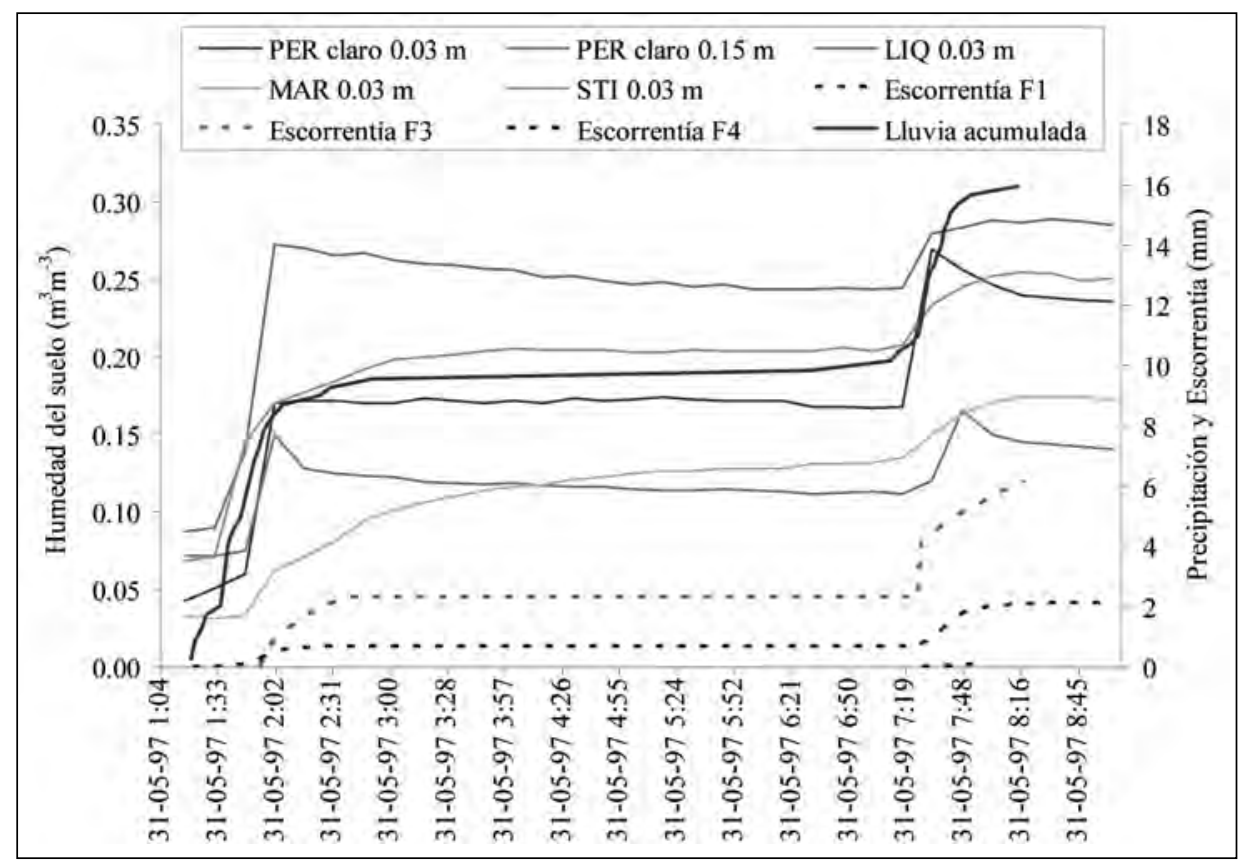

Figura 4. Evolución de la humedad del suelo a dos profundidades en cuatro diferentes geoformas durante dos eventos de precipitación en un mismo día y caudales generados en 3 aforadores. Permite ver que si el suelo está muy húmedo, unos pocos milímetros de lluvia son suficientes para generar de nuevo escorrentía. PER = pedimento cubierto de anuales y perennes; $L I Q$ = ladera cubierta de líquenes; MAR = ladera desnuda; STI = ladera N cubierta de esparto

\section{Erosión hídrica. Tipos y procesos}

En el desierto de Tabernas abundan muchas de las formas que produce la erosión hídrica: surcos (rigolas, acanaladuras, rills), cárcavas, pedestales, pináculos, túneles de sufusión, pequeños conos de deyección, bloques caídos, etc., producto de una variedad de procesos que pueden darse aisladamente o en grupos: escorrentía difusa, escorrentía concentrada, salpicadura, movimientos en masa y sufusión (Cantón y Solé, 2004c).

Los surcos suelen ser más conspicuos en la mayoría de laderas expuestas al S y SW. La salpicadura o splash da lugar a numerosos pináculos y pedestales (Fig. 5), que se conservan durante muchos años en las partes bajas de las laderas especialmente en orientaciones N, NE y E. Menos abundantes son los movimiento en masa de tipo deslizamiento, en general muy someros, que afectan áreas desde menos de un metro cuadrado a varias decenas de metros cuadrados en laderas de fuerte pendiente después de episodios lluviosos de cierta magnitud capaces de saturar el regolito superficial. En condiciones de extrema sequedad, el propio regolito puede sufrir pequeños movimientos en masa que afectan superficies siempre inferiores al metro cuadrado o incluso al decímetro cuadrado. 


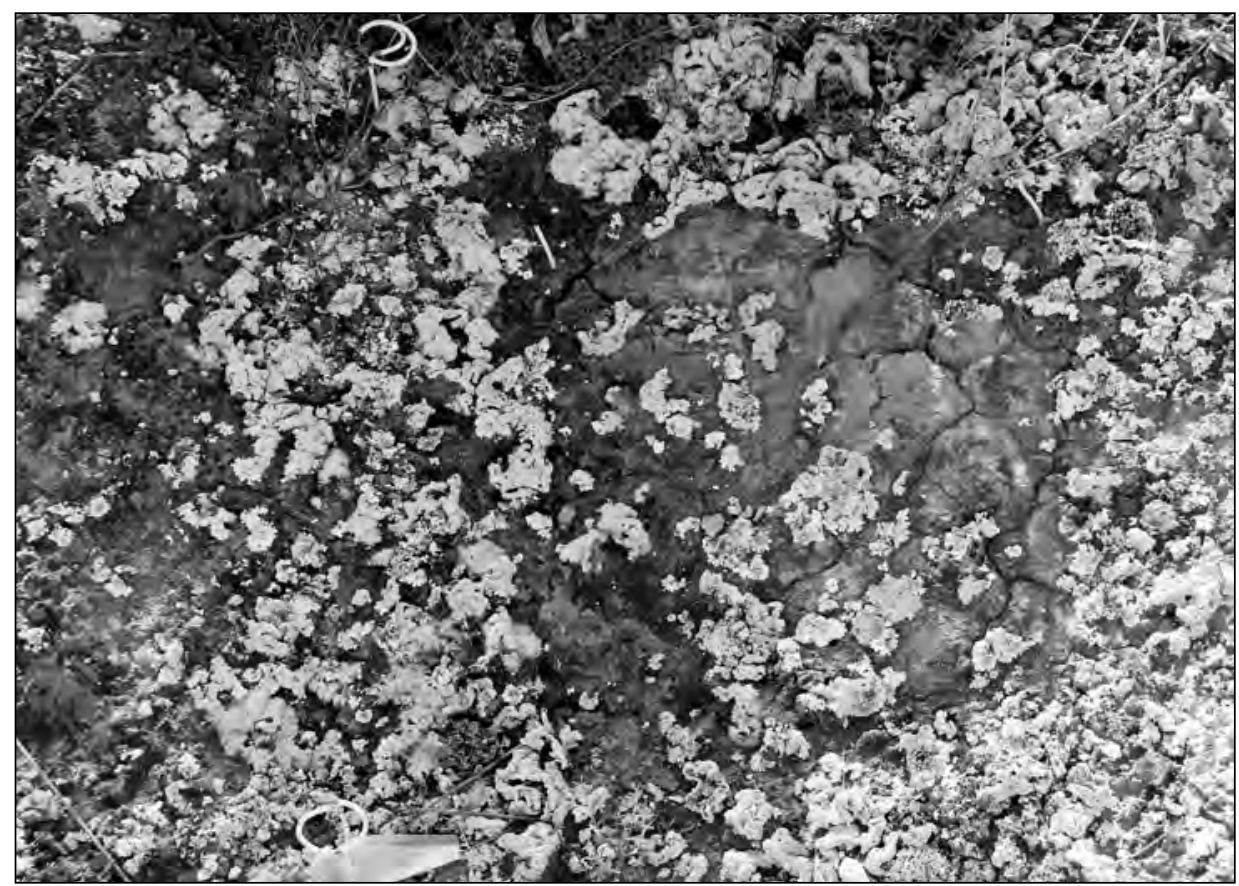

Figura 5. Superficie orientada al NE recubierta por líquenes (LIQ).

El fuerte contraste de estructura entre el suelo y/o regolito y el material parental subyacente, con sus correspondientes propiedades dispersivas y de cohesión, favorece la sufusión, es decir, la formación de túneles o pipes, que muchas veces son el inicio de cárcavas muy activas. En el desierto de Tabernas este proceso se produce sobre todo entre los rellenos sedimentarios cuaternarios, en general fuertemente edafizados y las margas o limolitas terciarias subyacentes (Cantón y Solé, 2004c).

Desde el año 1991 se está registrando la erosión en la zona experimental "El Cautivo" (Fig. 2) a diferentes escalas y con métodos específicos para cada una: puntual, ladera y cuenca.

Para la escala puntual se utilizaron copas de salpicadura (reciben sedimentos producidos por un área aproximadamente similar a la de las copas, es decir unos $100 \mathrm{~cm}^{2}$ ), parcelas cerradas de erosión de $0,24 \mathrm{~m}^{2}$ y clavos de erosión (registran los cambios en el nivel del suelo y su área de influencia no va más allá de unos pocos centímetros o decímetros cuadrados).

Para la escala de ladera se utilizan: a) clavos de erosión dispuestos en cuadrículas que cubren áreas de unos $100 \mathrm{~m}^{2}$, b) un perfilómetro láser en tres transectos perpendiculares a una cárcava incipiente y c) pequeñas estaciones de aforo de tipo H (USDA, 1979). 
Para las escala de micro-cuenca se utiliza un estación de aforo (máximo $340 \mathrm{~L} \mathrm{~s}^{-1}$ ) a la salida de la cuenca.

Además de la escala espacial se resumen los resultados registrados a diferentes escalas temporales (evento, estación y año).

\subsection{Escala puntual}

a) Copas de salpicadura

Durante los años de máxima erosión los suelos con costras físicas se erosionan mucho más $\left(3800 \mathrm{~g} \mathrm{~m}^{-2}\right)$ que los suelos con costras criptogámicas indiferenciadas $\left(1700 \mathrm{~g} \mathrm{~m}^{-2}\right)$ y éstos que los suelos cubiertos con líquenes $\left(338 \mathrm{~g} \mathrm{~m}^{-2}\right)$. La misma secuencia se produce durante el año de mínima erosión, pero con valores muy inferiores: a) $931 \mathrm{~g} \mathrm{~m}^{-2}$ en las costras físicas, b) $338 \mathrm{~g} \mathrm{~m}^{-2}$ en las costas indiferenciadas y c) $148 \mathrm{~g} \mathrm{~m}^{-2}$ en las costras liquénicas. La máxima recogida de sedimentos en un solo período y en un solo punto fue de $2.586 \mathrm{~g} \mathrm{~m}^{-2}$ para una precipitación total de $137 \mathrm{~mm}$, el $85 \%$ de la cual se produjo durante 20 días en el mes de Septiembre de 1997 (Downward, 2000).

Las tasas por unidad de superficie proporcionadas por las copas de salpicadura en realidad solo sirven para comparar la remoción puntual de sedimentos en diferentes tipos de superficie y los datos no pueden extrapolarse a verdaderas tasas de erosión de superficies mayores pues la exportación depende ya de otros procesos como la escorrentía.

b) Parcelas de erosión

Por el hecho de estar cerradas, es decir, aisladas del resto de la ladera, registran tasas de escorrentía limitadas y por ello la producción de sedimentos también puede ser limitada. Se han medido entre 1,6 y $32 \mathrm{~g} \mathrm{~m}^{-2}$ en laderas orientadas al N, NE y E, cubiertas por líquenes o plantas superiores, y entre 161 y $397 \mathrm{~g} \mathrm{~m}^{-2}$ en laderas orientadas al S, SW y W, desnudas o con líquenes degradados (Cantón, 2001; Canton et al., 2001a).

Estos datos son del mismo orden de magnitud que los producidos por lluvia simulada (55 $\mathrm{mm} \mathrm{h}^{-1}$ durante 30 minutos, lo que puede considerarse un evento extremo) (Solé-Benet et al., 1997).

c) Clavos de erosión

Dispuestos en grupos de 6, al azar, sobre áreas de $2 \mathrm{~m}$ x $2 \mathrm{~m}$. La mayor tasa de rebajamiento anual la registró la divisoria sin vegetación con 15,19 mm $\left(20810 \mathrm{~g} \mathrm{~m}^{-2}\right)$ mientras que la mayor tasa anual de deposición la registró una parcela orientada al $\mathrm{N}$ con una cubierta parcial de líquenes degradados, con 11,2 mm $\left(15344 \mathrm{~g} / \mathrm{m}^{-2}\right)$.

Las tasas medidas, si bien siguen el mismo orden que las tasas medidas con copas y microparcelas en los mismos tipos de superficie, son dos órdenes de magnitud superiores a las microparcelas y un orden de magnitud superior a las copas de salpicadura. 
Esto se debe a que a) los clavos registran erosión producida conjuntamente por la mayoría de los procesos (salpicadura, escorrentía concentrada, escorrentía difusa, pequeños movimientos en masa) en lugar de sólo por salpicadura como las copas y, b) la escorrentía actúa sobre longitudes de ladera mucho mayores que en las parcelas y además se trata de áreas abiertas.

\subsection{Escala de ladera o cárcava elemental}

Desde 1995 se monitorizan dos laderas, una orientada al SW y otra al NE, cada una de ellas con más de 80 clavos de erosión, distribuidos en una retícula de $1 \mathrm{~m}$. Después de 12 años, los promedios de erosión son relativamente similares a los producidos por las parcelas, es decir: 2,67 mm año ${ }^{-1}\left(3567,9 \mathrm{~g} / \mathrm{m}^{-2}\right)$ en la ladera orientada al SO y 1,19 $\mathrm{mm}$ año $\mathrm{o}^{-1}\left(1630,3 \mathrm{~g} / \mathrm{m}^{-2}\right)$ en la orientada al NE. Sin embargo, por tratarse de superficies mucho mayores, los máximos y mínimos son superiores a los alcanzados en las parcelas: así en un surco incipiente, se alcanzó un rebajamiento anual de $87 \mathrm{~mm}$.

El seguimiento durante 5 años mediante perfilometría láser de una ladera desnuda orientada al SO en la que se estaba desarrollando una cárcava, presenta valores anuales promedio de rebajamiento de $1,27 \mathrm{~mm}, 3,23 \mathrm{~mm}$ y 2,01 $\mathrm{mm}$ en el transecto alto, medio y bajo de la ladera. Sin embargo, estos valores promedio están fuertemente influidos por máximos de hasta $88 \mathrm{~mm}$ en el fondo del canal de desagüe mientras que el resto de la ladera permanece invariable (Fig. 6). Este valor es similar al máximo registrado con los clavos de erosión, como se indica en el párrafo anterior.

En los microcuencas F2 y F3, que pueden considerarse cárcavas elementales, se tratan en el siguiente apartado.

\subsection{Escala de cuenca (varias ha)}

Se seleccionó una pequeña cuenca $(1,88 \mathrm{ha})$ llamada $F 1$ y otras tres encajadas en ella: la $F 2\left(225 \mathrm{~m}^{2}\right)$, la $F 3\left(62 \mathrm{~m}^{2}\right)$ y la $F 4\left(5775 \mathrm{~m}^{2}\right)$. Las $F 2$ y F3 desprovistas de vegetación. La $F 4$, en la cabecera de la $F 1$, está casi completamente vegetada. La $F 1$ está formada por superficies vegetadas y no vegetadas.

Desde su instalación en 1991, se han registrado 83 eventos de escorrentía y prácticamente en todos ellos se recogieron sedimentos en alguna de las subcuencas. Solo la subcuenca de la parte alta, $F 4$, prácticamente no ha registrado erosión, por estar en gran parte cubierta de vegetación y porque la parte que no lo está, inmediata al aforador, ha alcanzado su perfil de equilibrio.

En general se comprueba que la producción de sedimentos es directamente proporcional a la escorrentía producida durante los eventos (Fig. 7). Sin embargo, se han registrado excepciones, cuando lluvias moderadas, no muy intensas y productoras de esco- 


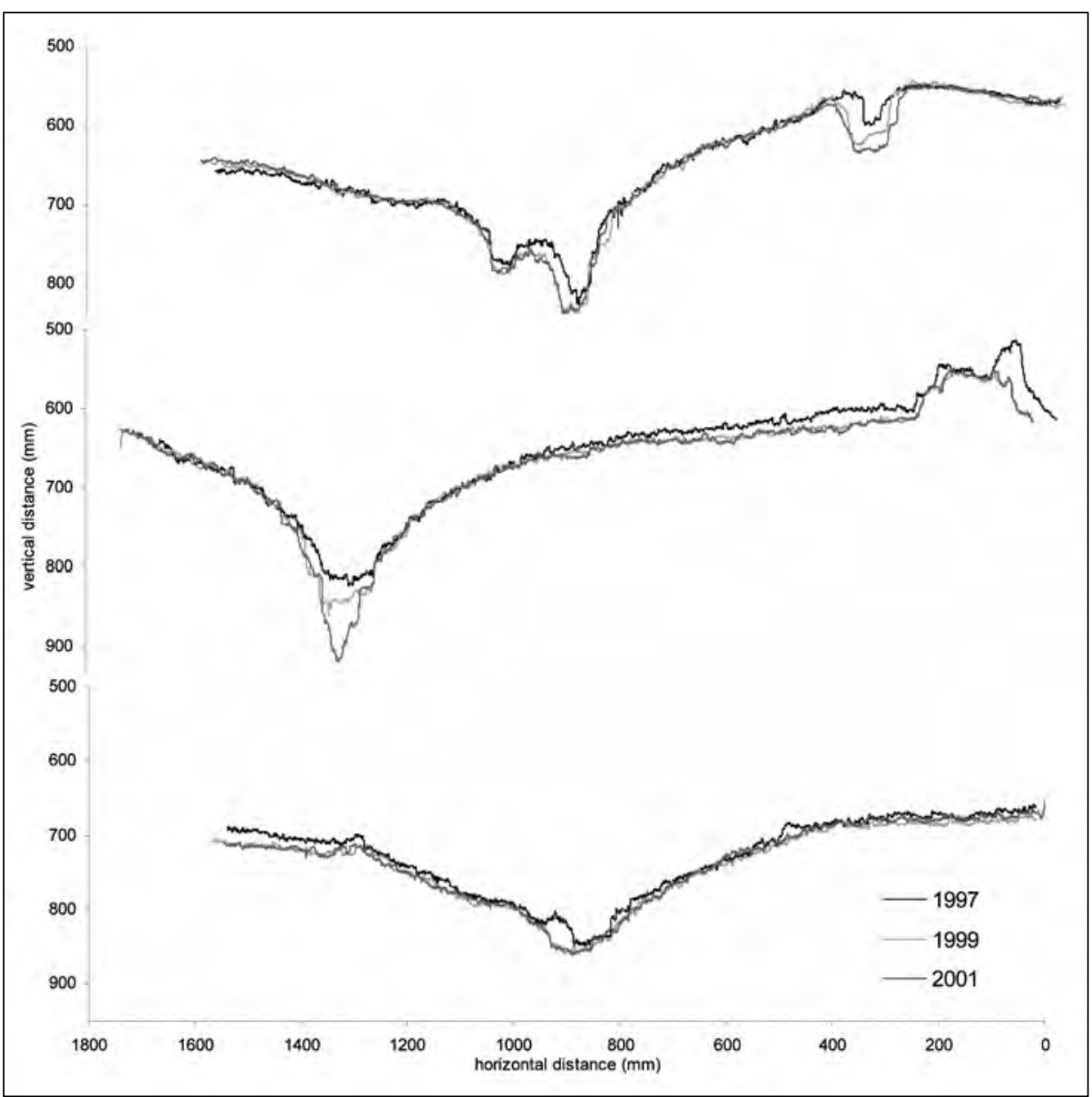

Figura 6. Evolución de un surco en una ladera desnuda de unos $10 \mathrm{~m}$ de longitud y $30^{\circ}$ de pendiente, orientada al SW, entre 1997 y 2001, representada por tres perfiles (perfilómetro láser) perpendiculares a la pendiente (zonas alta, media y baja)

rrentía moderada, han evacuado una cantidad desproporcionada de sedimentos. Esto ocurre tras largos períodos con lluvias muy pequeñas que no generan escorrentía, o muy poca, pero durante los cuales los abundantes ciclos humedad-desecación han generado gran cantidad de sedimentos que se acumulan en diversos puntos de la cuenca. La Fig. 8 contiene datos de algunos de estos eventos a modo de ejemplo.

Al igual que en la mayoría de zonas de malpaís, en la del desierto de Tabernas el principal mecanismo de generación de escorrentía es de tipo hortoniano, es decir que la escorrentía se genera cuando la intensidad de la lluvia supera la capacidad de infiltración del suelo. 


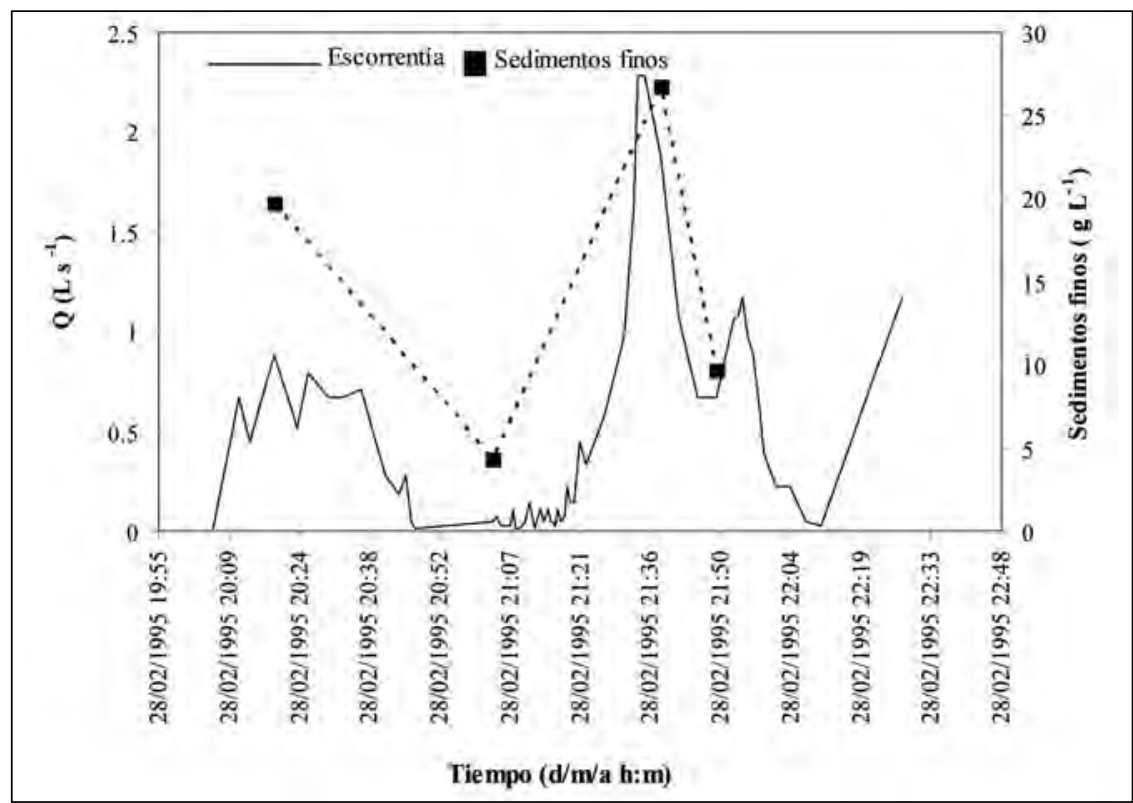

Figura 7. Hidrograma y sedimentos en suspensión durante un evento "promedio" de escorrentía de baja magnitud, en el que la producción de sedimentos es directamente proporcional a la escorrentía

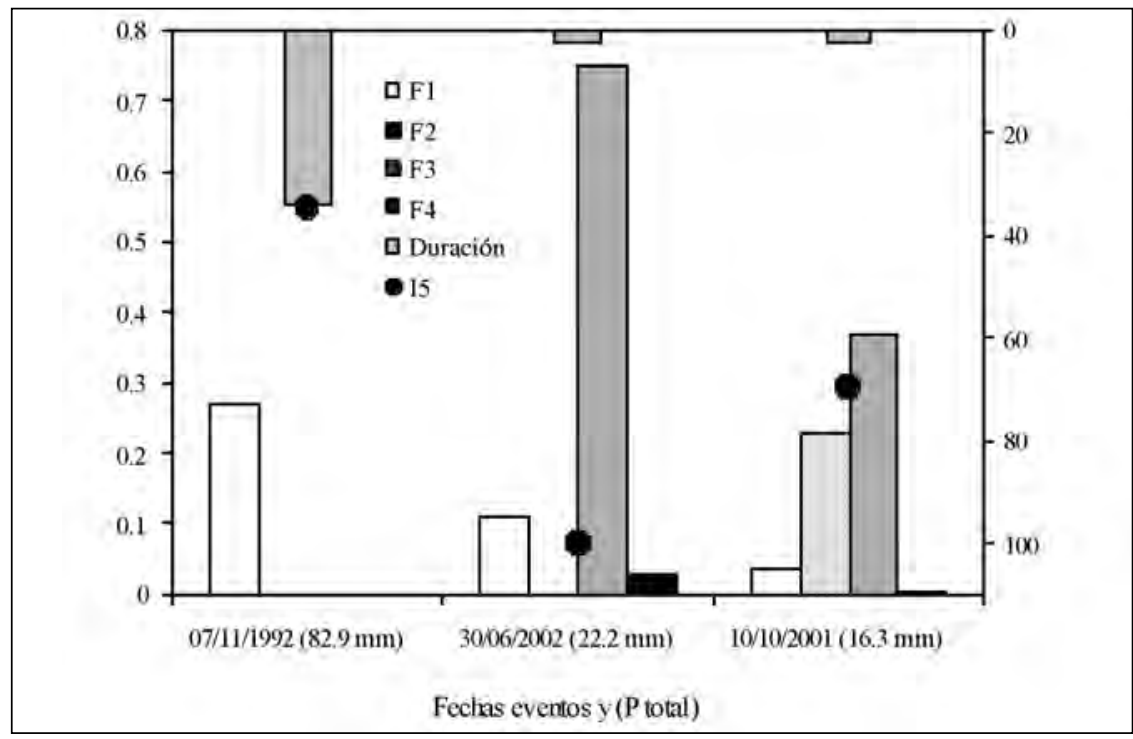

Figura 8. Tres tipos de eventos especiales productores de sedimentos, con precipitaciones con distintas magnitud, intensidad y duración. Cada evento produce diferentes cantidades de sedimentos en los distintos aforadores de la cuenca (F1 es la cuenca total, F2 y F3 son microcuencas elementales y F4 es la cabecera cubierta casi totalmente de vegetación). Solo los dos eventos de la derecha producen sedimentos en los 4 aforadores (en uno de los eventos en $F 2$ se perdieron los datos) 
En la tabla 2 se comparan las tasas de erosión producidas en las cuatro microcuencas durante eventos representativos de un año seco y un año lluvioso. Se observa que la relación entre pluviometría y sedimentos movilizados es compleja. Además de cierta relación con el volumen de la precipitación, la producción de sedimentos es afectada especialmente por la distribución temporal de la misma, tanto a escala de minutos (intensidad de la lluvia) como a escala diaria (humedad antecedente) y a escala mensual e incluso anual (preparación de sedimentos a lo largo de los meses previos). En la cuenca principal, la tasa anual registrada en 2003-04, una de las mayores de todo el período de seguimiento, fue de $1647,37 \mathrm{~g} \mathrm{~m}^{-2}$, es decir, $16,5 \mathrm{t} \mathrm{ha}^{-1}$. La tasa anual promedio de todo el período de seguimiento es un orden de magnitud inferior a dicha cifra, es decir, entre 1 y $2 \mathrm{t} \mathrm{ha}^{-1}$.

En el desierto de Tabernas sólo el 16\% de las lluvias exceden el umbral de escorrentía más frecuente $(9 \mathrm{~mm})$. Sin embargo, el papel del $84 \%$ restante no es despreciable ya que la sucesiva humectación-desecación es esencial para la meteorización del material parental, proporcionando sedimentos fáciles de transportar. En la tabla 3 se ve como la cantidad de material meteorizado (en periodos de 6 meses) está relacionada con el número de lluvias mayores de $3 \mathrm{~mm}$ y los sedimentos generados por erosión en una micro-parcela de regolito completamente desnudo están relacionados con el número de eventos mayores de $9 \mathrm{~mm}$.

Tabla 2. Producción de sedimentos $\left(\mathrm{g} \mathrm{m}^{-1}\right)$ registrada para las microcuencas $F 1, F 2$ y F3 durante los años hidrológicos 2002-2003 (seco) y 2003-2004 (húmedo)

\begin{tabular}{|l|c|c|c|c|c|c|}
\hline & Evento & $\begin{array}{c}\mathbf{P} \\
(\mathbf{m m})\end{array}$ & $\begin{array}{c}\text { max } \mathbf{I}_{\mathbf{5}} \\
\left(\mathbf{m m} \mathbf{h}^{-1}\right)\end{array}$ & $\mathbf{F 1}$ & $\mathbf{F 3}$ & $\mathbf{F 4}$ \\
\hline \multirow{2}{*}{$2002-03$} & $14 / 11 / 02$ & 23.8 & 19.0 & $0.03^{*}$ & 417.12 & $0.17^{*}$ \\
& $10 / 01 / 03$ & 15.4 & 7.0 & $0.91^{*}$ & 0 & 0 \\
& $25 / 02 / 03$ & 14.0 & 21.0 & 0.26 & 16.13 & 0.09 \\
& $22 / 04 / 03$ & 7.6 & 41.9 & 0.006 & 0 & 0 \\
& anual & 135.9 & 41.9 & $>1.26^{*}$ & 433.25 & 0.26 \\
\hline \multirow{2}{*}{$2003-04$} & $07 / 10 / 03$ & 17.9 & 80.3 & 2.55 & $2,635.58$ & n.d. \\
& $18 / 11903$ & 62.4 & 14 & 92.20 & $23,063.27$ & 65.47 \\
& $23 / 11 / 03$ & 19.3 & 31.4 & 396.42 & $1,042.81$ & 11.6 \\
& $09 / 12 / 03$ & 25.6 & 21.0 & 14.51 & 0 & 25.58 \\
& $28 / 03 / 04$ & 31.0 & 10.5 & 80.63 & 156.42 & 20.33 \\
& $09 / 04 / 04$ & 56.7 & 31.4 & 961.97 & 208.56 & 160.70 \\
& $15 / 04 / 04$ & 20.4 & $7-0$ & 28.15 & 8.06 & $0.17 *$ \\
& $02 / 05 / 04$ & 7.8 & 28.0 & 23.95 & 12.9 & $5.87 *$ \\
& $13 / 06 / 04$ & 9.6 & 63.0 & 46.99 & 270.7 & 12.85 \\
& anual & 347.9 & 80.3 & $1,647.37$ & $27,398.3$ & 302.57 \\
\hline
\end{tabular}

* indica que en dichos eventos los sedimentos en suspensión no se registraron. n.d. = no disponible 


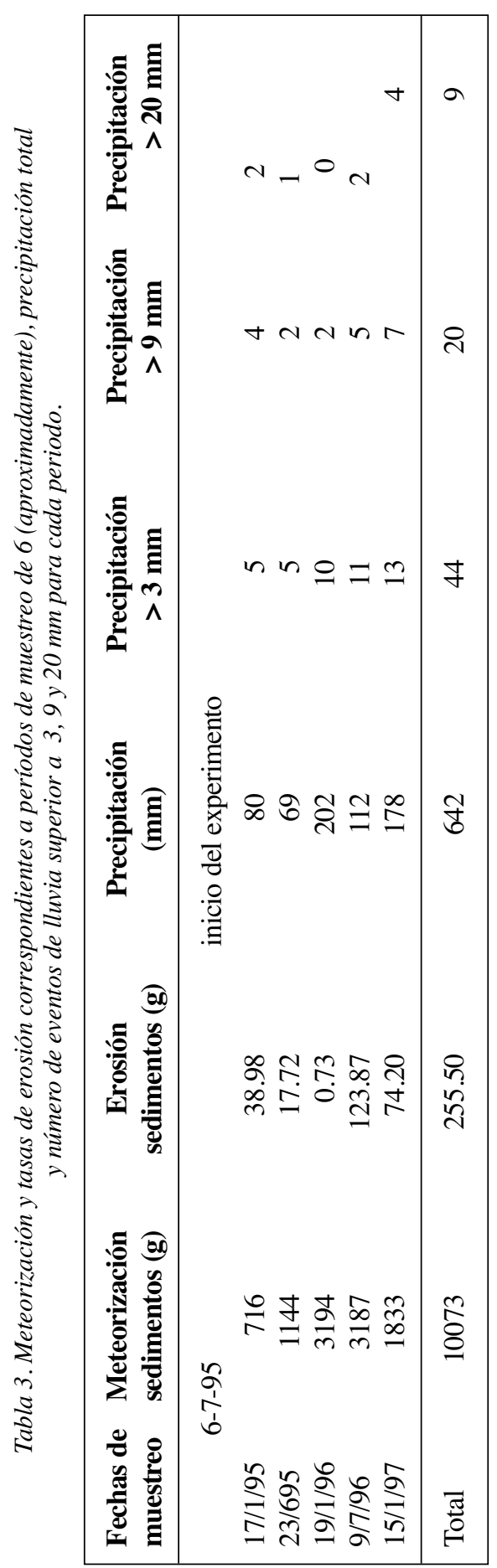


Como la mayoría de años las tasas anuales de erosión son inferiores a las de meteorización, el regolito se acumula. La limitación a los procesos de erosión en El Cautivo no es la disponibilidad de material meteorizado, sino la frecuencia y magnitud de los eventos capaces de evacuar este material.

Por otra parte, la modelización espacialmente distribuida de la escorrentía (Cantón et al., 2002) ha permitido explorar los flujos de agua entre tipos de cubiertas y demuestra que normalmente no se genera escorrentía en las superficies vegetadas con anuales y perennes (pedimentos), mientras que las superficies no vegetadas generan la mayor parte de la escorrentía de la cuenca $F 1$. Las superficies con cubierta criptogámica se caracterizan por altos coeficientes de escorrentía, la cual se infiltra en los pedimentos situados aguas abajo, reduciendo de esta forma el riesgo de erosión y constituyendo un aporte importante de agua para el pedimento y su matorral. En las laderas vegetadas, sólo durante momentos específicos de elevada intensidad de lluvia, con picos importantes de escorrentía, ésta se concentra en determinadas zonas y alcanza los cauces.

Por lo tanto, los procesos de erosión de este sistema están limitados aparte de por la magnitud de la de precipitación y la intensidad de la misma, por: a) los tipos de superficies que lo integran (superficies vegetadas, tanto de matorral como con líquenes, con tasas de erosión muy bajas, que constituyen más de la mitad del área de estudio, y un $30 \%$ de superficie desnuda que contribuye eficazmente a la producción de sedimentos); b) por la organización espacial de dichas superficies vegetadas, con cubierta liquénica y desnudas.

\section{Discusión y conclusiones}

Las tasas de erosión proporcionadas con los diferentes métodos sólo son válidos cuando se conocen perfectamente las condiciones en los que se han tomado: área de contribución, tiempo, momento y duración de las mediciones. En general, los métodos puntuales en breves intervalos de tiempo registran tasas de erosión mucho mayores que métodos que cubren amplias áreas durante mayores períodos (Yair et al., 1980). En las zonas de badlands las tasas de erosión varían grandemente tanto a escala espacial como temporal: puntos con elevada productividad de sedimentos durante un determinado momento son muy estables en otro momento. La alternancia en la variabilidad de las tasas de erosión es especialmente cierta en la escalas más puntuales.

A escalas temporales de larga duración, las tasas de erosión en los badlands de Tabernas son más bien bajas, del orden de $0,7 \mathrm{~mm} \mathrm{a}^{-1}$ como han demostrado Cantón et al (2001b) mediante meteorización experimental, valor que se aproxima a las tasas de sedimentación de $0,2 \mathrm{~mm} \mathrm{a}^{-1}$ en los últimos 8000 años dadas por Nogueras et al. (2000) mediante el estudio de los granos de polen en una zona de sedimentación protegida de la erosión dentro del área acarcavada. Hay que tener en cuenta que las tasas de sedimentación son siempre inferiores a las de erosión dado que en estas últimas hay una parte importante de elementos muy finos y/o solubles que no depositan cerca del área fuente o que son evacuados fuera del área. 
Estas tasas contrastan con el aspecto del paisaje, profundamente abarrancado, con una muy prolija red de drenaje y alta proporción de suelo desnudo. Dicho aspecto se debe a la acumulación de áreas erosionadas durante siglos, tal vez algunos miles de años. A partir de cierta cobertura de vegetación los procesos se retroalimentan hacia "más vegetación", pero por debajo de ese umbral, se retroalimentan hacia "más erosión" (Gallart et al., 2002). Una vez iniciado un ciclo de erosión, la vegetación es normalmente incapaz de detenerla y colonizar esa área por lo que, aunque el proceso erosivo sea lento, las áreas erosionadas se van acumulando y agrandando. Aparte de eso, la erosión puede haber sido más rápida en cortos periodos de otras épocas, como probablemente durante la Pequeña Edad del Hielo de la Edad Moderna.

Las tasas registradas en Tabernas coinciden con las que encuentran otros autores en otras áreas semiáridas Mediterráneas (Yair et al., 1982) y se deben principalmente a la escasez de precipitaciones y la muy baja frecuencia de lluvias erosivas. Sin embargo, las tasas de erosión en el malpaís de Tabernas son aún mucho mayores que las de las zonas vecinas de alrededor con otras litologías, como es el caso de la Rambla Honda sobre micasquistos donde se citan tasas de erosión inferiores a $1 \mathrm{t} \mathrm{ha}^{-1} \mathrm{a}^{-1}$ (Solé-Benet et al., 2003).

La vegetación del área tiene un marcado patrón espacial, fuertemente asociado al grado de erosión del sustrato. A grandes rasgos hay dos clases de ambientes (y comunidades vegetales asociadas): a) los erosivos, típicos de las laderas con fuerte pendiente orientadas al S, SW y W, prácticamente desnudos, y b) los estabilizados, típicos de las laderas con pendiente suave orientadas al N, NE y E, que concentran casi toda la vegetación. Las costras biológicas, a menudo dominadas por líquenes terrícolas, están ampliamente extendidas en nuestra área y ocupan típicamente la parte superior de las laderas estabilizadas, donde la escorrentía saliente es mayor que la entrante y la baja disponibilidad de agua dificulta el desarrollo de plantas vasculares haciendo competitivas a las costras que, a su vez, aumentan la escorrentía, reforzando el patrón. En conjunto, la superficie erosionada representa un $33 \%$ del total, la cubierta por costras biológicas un $32 \%$ y el resto soporta casi toda la vegetación de plantas vasculares (Canton, 2001), con coberturas usualmente entre el 20 y el $40 \%$ y segregación espacial entre anuales y perennes, formando mosaicos.

En las áreas erosionadas tanto la meteorización como la escorrentía y la erosión alcanzan a menudo los máximos valores y el movimiento del agua y los sedimentos están controlados por factores como las costras físicas, cobertura de piedras, pendiente, microtopografía, etc. (Solé et al., 1997; Cantón, 2001). En las áreas cubiertas por costras biológicas, los coeficientes de escorrentía son similares a los del suelo desnudo pero al mismo tiempo la exportación de sedimentos está muy reducida. En las manchas de vegetación vascular tanto la meteorización como la escorrentía y la erosión alcanzan sus mínimos (Cantón, 2001). Aunque este efecto de las costras y las plantas depende bastante de los grados de cobertura de las mismas. Las relaciones de los flujos de escorrentía y sedimentos con las coberturas de las plantas son negativas y a menudo asintóticamente no lineares (Solé-Benet et al., 1997). Así, el incremento de la densidad de la 
vegetación causa un decremento exponencial de la escorrentía y exportación de sedimentos. El efecto de las plantas y de su estructura espacial es además dinámico y especie-específico (Puigdefábregas y Sánchez, 1996).

Este malpaís es, en suma, un mosaico de teselas que concentra muchas de las formas de erosión de la mayoría de paisajes fluviales, y muy en especial los de zonas áridas. Un clima Mediterráneo semiárido extremo, prácticamente único en Europa, y una particular litología con alternancia de margas yesíferas y calcarenitas, junto con una baja intensidad de usos humanos durante largo tiempo, han dado lugar a una red de drenaje muy desarrollada y explican la gran variedad de geoformas y hábitats de este paisaje bien conservado que debería ser objeto del mayor grado de protección posible dado su enorme interés científico y paisajístico.

\section{Referencias bibliográfícas}

Alexander, R.W., CALvo, A. (1990). The influence of lichens on slope processes in some Spanish badlands. In Vegetation and Erosion (J.B.Thornes, ed.) Wiley, Chichester, Reino Unido.

BOWYER-BOWER, T.A.S., 1993. Effects of rainfall intensity and antecedent moisture on the steady-state infiltration rate in a semi-arid region. Soil Use and Management, 9: 69-76.

CANTÓN, Y. (2001). Efectos hidrológicos y geomorfológicos de la cubierta y propiedades del suelo en paisaje de cárcavas. Tesis doctoral. Universidad de Almeria. Spain. 394 p. Publicada como CD-ROM. Universidad de Almería.

CAntón, Y., Domingo, F., SolÉ-Benet, A. Puigdefábregas, J. (2001a). Hydrological and erosion response of a badlands system in semiarid SE Spain. Journal of Hydrology, 252: $65-84$.

Cantón, Y., Solé-Benet, A., Queralt, I., Pini, R. (2001b). Weathering of a gypsumcalcareous mudstone under semi-arid environment at Tabernas, SE Spain: laboratory and field-based experimental approaches. Catena, 44:111-132.

Cantón, Y., Domingo, F., Solé-Benet, A., Puigdefábregas, J. (2002). A physicallybased distributed model for runoff generation for the Tabernas badlands, SE Spain. Hydrological Processes, 16: 2621-2643.

CANTÓN, Y., SolÉ-BENET, A., LÁZARO, R. (2003). Soil-geomorphology relations in gypsiferous materials of the Tabernas desert (Almería, SE Spain) Geoderma, 115: 193-222.

CANTÓN, Y., DEl BARRIO, G., SOlÉ-BENET, A., LÁZARO, L. (2004a). Topographic controls on the spatial distribution of ground cover in a semiarid badlands area. Catena, 55: 341-365.

Cantón, Y., SolÉ-Benet, A., Domingo, F. (2004b). Temporal and spatial patterns of soil moisture in semiarid badlands of SE Spain. Journal of Hydrology, 285: 199-214. 
CAntón, Y., SolÉ-Benet, A. (2004c). Geomorfología y procesos actuales. En Subdesiertos de Almería: naturaleza de cine (Mota, J., Cabello, J., Cerrillo, M.I., Rodríguez-Tamayo, M.L., eds.). pp 39-50, Consejería de Medio Ambiente, Junta de Andalucía, Sevilla.

CAPEL MolinA, J.J. (1982). La aridez en la península Ibérica. Algunos índices bioclimáticos. En: Homenaje almeriense al botánico Rufino Sagredo. Instituto de Estudios Almerienses. Almería.

Chamizo, S., LÁzaro, R., Cantón, Y., Domingo, F., Solé-Benet, A. (2008). Efectos de las costras bióticas y abióticas sobre la infiltración en ambientes semiáridos. En Agua y Cultura, VII Simposio del agua en Andalucía (J.A. López-Geta, J.C. Rubio y M. Martín, eds.) Publicaciones del IGME, serie Hidrogeología y aguas subterráneas $\mathrm{n}^{\mathrm{o}} 25$, pp. 199-210. Madrid.

Doorembos, J., PruitT, W.O. (1976). Las necesidades de agua de los cultivos. Estudio FAO - Riego y Drenaje, 24, 194 p, FAO, Roma.

DOWNWARD, K. (2000). Relationship between surface crusts and erosion in the Tabernas badlands, Almeria, SE Spain. Tesis doctoral inédita, 248 p + Anexos, Universidad de Wolverhampton, Reino Unido.

EMERSON, V.V. (1967). A classification of soil aggregate based on their consistency in water. Australian Journal of Soil Research, 5: 47-57.

FAO-ISRIC-ISSS, (1998). World reference base for soil resources. FAO, Roma.

Gallart, F., Solé-Benet, A., Puigdefábregas, J., LÁZAro, R. (2002). Badland systems in the Mediterranean. En Dryland rivers. Hydrology and geomorphlogy of semi-arid channels (Bull, L., Kirkby, M. eds.), pp 299-326, John Wiley \& sons, Chichester, Reino Unido.

Harvey, A.M., CAlvo, A. (1991). Process interactions and rill development on badland and gully slopes. Zeitschrift für Geomorphologie Supplementband, 83: 175-194.

KleVerlaAn, K. (1989). Neogene history of the Tabernas basin (SE Spain) and its Tortonian submarine fan development. Geologie en Mijnbouw, 68: 421-432.

LÁzaro, R., Alexander, R.W. Puigdefábregas, J. (2000). Cover distribution patterns of lichens, annuals and shrubs in the Tabernas Desert, Almería, Spain. En Vegetation Mapping: from patch to planet (Alexander, R.W., Millington, A.C., eds.), pp 19-40. John Wiley \& Sons, Ltd. Chichester, Reino Unido.

LÁZARo, R. Rodríguez-TAmayo, M.L., Ordiales, R., Puigdefábregas, J. (2004). El clima. En Subdesiertos de Almería: naturaleza de cine (Mota, J., Cabello, J., Cerrillo, M.I., Rodríguez-Tamayo, M.L., eds.), pp 62-79, Consejería de Medio Ambiente, Junta de Andalucía, Sevilla. 
LÁZARO-SUAU, R. (1995). Relaciones entre vegetación y geomorfología en el área acarcavada del Desierto de Tabernas. Tesis Doctoral, Fac. Biología, Universidad de Valencia, Valencia.

Neumann, H. (1961). El clima del sudeste de España. Estudios Geográficos, 21 (79): 171-209.

Nogueras, P., Burjachs, F., Gallart, F., Puigdefabregas, J. (2000). Recent gully erosion in the El Cautivo badlands (Tabernas, SE Spain). Catena, 40: 203-215.

PUIGDEFÁBREGAS, J., SÁNCHEZ, G. (1996). Geomorphological Implications of vegetation patchiness on semi-arid slopes. En Advances in Hillslope Processes (Anderson, M. G., Brooks, S. M., eds.), vol 2, pp 1027-1060, John Wiley \& Sons, Chichester, Reino Unido.

Rohdenburg, H., SAbelberg, U. (1973). Quartäre Klimazyklen im westlichen Mediterrangebiet und ihre. Auswirkungen auf die Relief- und Bodenentwicklung. Catena, 1: 71-80.

Sole-Benet, A., Calvo, A., Cerdà, A., lazaro, R., Pini, R., Barbero, J. (1997). Influences of micro-relief patterns and plant cover on runoff related processses in badlands from Tabernas (SE Spain). Catena, 31: 23-38.

Solé-Benet, A., Cantón, Y., Domingo, F., DelBarrio, G., Lázaro, R., Domene, M.A., VidAl, S., PuigdefábregAS, J. (2003). Long term hydrological monitoring of two micro-catchments in semi-arid SE Spain. En Interdisciplinary approaches in small catchment hydrology: Monitoring and research (Holko, L., Miklánek, P., eds.), IHP-VI, Technical Documents in Hydrology n ${ }^{\circ}$ 67, pp 183-188, UNESCO, Paris.

TAYLOR, R.K., SMITH, T.J. (1968). The engineering geology of clay minerals: swelling, shrinking and mudrock breakdown.. Clay Minerals, 21: 235-260.

TerZaghi, K., PeCK, R.B. (1967). Soil Mechanics in Engineering Practice. 2nd Ed., John Wiley \& sons, New York.

THORNTHWAITE, C.W. (1948). An approach towards a rational classification of climate. The Geography Review, 38 55-94.

USDA, (1979). Field Manual for Research in Agricultural Hydrology. USDA Handbook $\mathrm{n}^{\circ}$ 224. USDA, Washington, DC, USA.

VAlentin, C., BREsSOn, L.M., (1992). Morphology, genesis and classification of surface crusts in loamy and sandy soils. Geoderma, 55 225-245.

WEIJEMARS, R. (1991). Geology and tectonics of the Betic zone, SE Spain. Earth Science Reviews, 31: 153-236.

YAIR, A., LAVEE, H., BRYAN, R., ADAR, E. (1980). Runoff and erosion proceses and rates in the Zin valley badlands, Northern Negev, Israel. Earth Surface Processes, 5: 205-225. 